\title{
Synthesis and Properties of Block Copolymers Based on Carboxyl-Terminated Polydimethylsiloxane and Aromatic Polyamides
}

\author{
Masa-aki KaKIMOTo, Mikio KAJIYAMA, and Yoshio IMAI \\ Department of Textile and Polymeric Materials, \\ Tokyo Institute of Technology, Meguro-ku, Tokyo 152, Japan
}

(Received July 28, 1986)

\begin{abstract}
Polysiloxane-aramid block copolymers were synthesized by a one-pot two-step method of direct polycondensation using triphenyl phosphite and pyridine as the condensing agents. Amine-terminated aramid oligomers were prepared by the reaction of 3,4'-oxydianiline and isophthalic acid, and subjected to polycondensation with $\alpha, \omega$-bis(10-carboxydecyr)polydimethylsiloxane to give block copolymers with inherent viscosities of $0.13-0.25 \mathrm{dl} \mathrm{g}^{-1}$. They were soluble in amide-type solvents like $N, N$-dimethylacetamide and gave translucent and ductile films by casting from the solutions. These block copolymers start to decompose around $300^{\circ} \mathrm{C}$. These properties are very similar to those of block copolymers derived from $\alpha, \omega$-bis (3aminopropyl)polydimethylsiloxanes and carboxyl-terminated aramid oligomers.
\end{abstract}

KEY WORDS Polydimethylsiloxane-Aramid Block Copolymers / Direct

Polycondensation / Solubility / Thermal Behavior / Tensile Properties /

In an effort to synthesize novel condensation-type multi-block copolymers, ${ }^{1-5}$ we have begun to investigate the synthesis of polysiloxane-aramid (aromatic polyamide) block copolymers. Our previous work involved the preparation of block copolymers from the direct polycondensation of $\alpha, \omega$-bis(3aminopropyl)polydimethylsiloxanes with carboxyl-terminated aramid oligomers using triphenyl phosphite and pyridine as the condensing agents. ${ }^{6}$ The polysiloxane-aramid block copolymers obtained by this method, however, were not of sufficiently high molecular weight, probably because of the low reactivity of aliphatic amino groups on the terminal positions of the polysiloxane oligomers with the carboxylic functions in direct polycondensation using these condensing agents.

An alternate promising route for the synthesis of polysiloxane-aramid block copolymers is that from the reactions of carboxyl- terminated polysiloxanes with amine-terminated aramid oligomers. In fact, another multi-block copolymers such as polyoxyethylene - aramid $^{1,2}$ and polybutadiene-aramid ${ }^{3-5}$ were sucessfully prepared in high molecular weight from combinations of the corresponding carboxyl-terminated soft-block oligomers and amine-terminated aramid oligomers through direct polycondensation. This article deals with the synthesis and characterization of polysiloxane-aramid block copolymers from $\alpha, \omega$-bis(10-carboxydecyl)polydimethylsiloxane and amine-terminated aramid oligomers.

\section{EXPERIMENTAL}

\section{Materials}

$\alpha, \omega$-Bis(10-carboxydecyl)polydimethylsiloxane (PSX-diacid), whose number average molecular weight was 4200 , was supplied from Toshiba Silicone Co., Ltd., Tokyo, and dried 
at $120^{\circ} \mathrm{C}$ for $1 \mathrm{~h}$ in vacuo. 3,4'-Oxydianiline (3,4-ODA) and isophthalic acid (IPA) were purified by recrystallization from chloroformhexane and aqueous ethanol, respectively. Triphenyl phosphite, pyridine, $N$-methyl-2pyrrolidone (NMP), $N, N$-dimethylacetamide (DMAc), and dioxane were purified by distillation. Cetyltrimethylammonium chloride (CTMAC) was used as received.

\section{Polymerization}

Block Copolymer Id. A mixture of $1.60 \mathrm{~g}$ ( $8 \mathrm{mmol})$ of $3,4^{\prime}-$ ODA, $1.25 \mathrm{~g}(7.5 \mathrm{mmol})$ of IPA, $5 \mathrm{ml}$ of triphenyl phosphite, and $1.2 \mathrm{~g}$ of CTMAC in $6 \mathrm{ml}$ of pyridine and $18 \mathrm{ml}$ of NMP was heated with stirring at $100^{\circ} \mathrm{C}$ for $2 \mathrm{~h}$ under nitrogen. To the reaction mixture, $2.10 \mathrm{~g}$ $(0.5 \mathrm{mmol})$ of PSX-diacid and $6 \mathrm{ml}$ of dioxane were added, and the mixture was stirred at $100^{\circ} \mathrm{C}$ for another $4 \mathrm{~h}$. The resultant polymer was isolated by pouring the mixture into 11 of methranol.

The product was purified by reprecipitation from DMAc-methanol, followed by successive washings with hot methanol and hot tetrachloromethane and drying at room temperature in vacuo. The yield was $3.14 \mathrm{~g}(68 \%)$. The inherent viscosity of the polymer in DMAc was $0.22 \mathrm{dlg}^{-1}$, measured at a concentration of $0.5 \mathrm{~g} \mathrm{dl}^{-1}$ at $30^{\circ} \mathrm{C}$. The infrared (IR) spectrum $(\mathrm{KBr})$ exhibited absorptions at 3300 $\mathrm{cm}^{-1}(\mathrm{~N}-\mathrm{H}), 1650 \mathrm{~cm}^{-1}(\mathrm{C}=\mathrm{O})$, and 1090 and $1010 \mathrm{~cm}^{-1}(\mathrm{Si}-\mathrm{O}-\mathrm{Si})$. The ${ }^{1} \mathrm{H}$ - nuclear magnetic resonance (NMR) spectrum $\left(\mathrm{D}_{2} \mathrm{SO}_{4}\right)$ showed peaks at $0 \mathrm{ppm}\left(\mathrm{s}, \mathrm{CH}_{3}\right)$ amd $7.2-$ $7.7 \mathrm{ppm}$ (m, aromatic $\mathrm{H})$.

Other block copolymers were prepared by similar procedures.

\section{Measurements}

IR spectra and ${ }^{1} \mathrm{H}$ NMR spectra were recorded on a Hitachi EP-G3 spectrophotometer and a JEOL Model FX-90Q Fourier transform spectrometer, respectively. Differential thermal analysis (DTA) and thermogravimetry (TG) were performed with Shimadzu thermal analyzers DTA-30M and TGA-30M, respectively. Differential scanning calorimetry (DSC) was performed with a Daini Seikosha SSC-560 differential scanning calorimeter. Tensile properties were determined from stress-strain curves obtained with a Toyo Baldwin Tensilon UTM-III at an elongation rate of $20 \% \mathrm{~min}^{-1}$. Measurements were performed at room temperature with film specimens $(5 \mathrm{~mm}$ wide, $35 \mathrm{~mm}$ long, and about $0.1 \mathrm{~mm}$ thick) and the average of at least five individual determinations was taken.

\section{RESULTS AND DISCUSSION}

\section{Synthesis of Block Copolymers}

Polysiloxane-aramid block copolymers were synthesized according to eq 1 by the one-pot two-step procedure reported previously. ${ }^{1-5}$ The PSX-diacid used in this study had a number average molecular weight $\left(\bar{M}_{n}\right)$ of 4200 .

In the first step, solutions of amine-terminated aramid oligomers with $\bar{M}_{n}$ s of 1800 7000 were prepared by reactions of a calculated excess of 3,4'-ODA with IPA in the presence of triphenyl phosphite and pyridine in NMP. In the second step, PSX-diacid was added to the just prepared solutions and polycondensation was continued to form polysiloxane-aramid block copolymers I.

For the synthesis of polyoxyethylenearamid and polybutadiene-aramid multiblock copolymers, direct polycondensation using triphenyl phosphite and pyridine as the condensing agents in NMP proceeded in a homogeneous solution. ${ }^{1-5}$ In the present case, however, the preparation of polysiloxanearamid block copolymers under similar conditions was unsuccessful because of the insoluble nature of PSX-diacid in polar solvents like NMP. PSX-diacid was soluble in hydrocarbons, chlorinated hydrocarbons, and ether solvents such as dioxane. Cetyltrimethylammonium chloride (CTMAC) has been reported to be an effective additive in the direct poly- 


$$
\begin{aligned}
& (\mathrm{x}+1) \mathrm{H}_{2} \mathrm{N-Ar- \textrm {NH } _ { 2 }}+\mathrm{x} \underset{\mathrm{O}}{\mathrm{HOC}} \|_{0}^{\mathrm{COH}}
\end{aligned}
$$

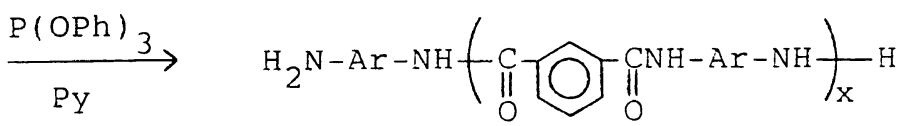

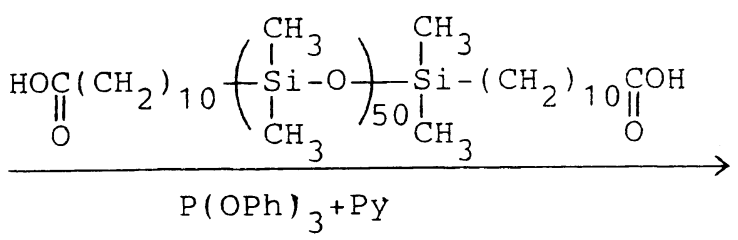

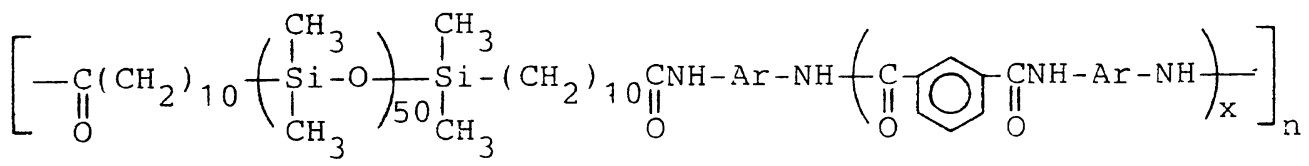

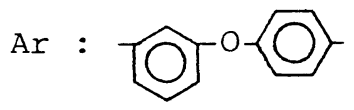

\begin{tabular}{|c|c|c|c|c|}
\hline \multirow{3}{*}{$\begin{array}{c}\bar{M}_{n} \text { of aramid } \\
\text { block }\end{array}$} & \multirow{3}{*}{$\begin{array}{c}\begin{array}{c}\text { Polysiloxane } \\
\text { content }^{\mathrm{a}}\end{array} \\
\frac{\mathrm{o}}{\%}\end{array}$} & \multicolumn{3}{|c|}{ Block copolymer } \\
\hline & & \multirow{2}{*}{ Code } & Yield & $\eta_{\mathrm{inh}}{ }^{\mathrm{b}}$ \\
\hline & & & $\%$ & $\mathrm{dl} \mathrm{g}^{-1}$ \\
\hline 1800 & 69 & Ia & 58 & 0.13 \\
\hline 2500 & 64 & $\mathrm{Ib}$ & 55 & 0.19 \\
\hline 3500 & 54 & Ic & 57 & 0.18 \\
\hline 5000 & 44 & Id & 68 & 0.22 \\
\hline 7000 & 37 & Ie & 75 & 0.25 \\
\hline
\end{tabular}

Table I. Synthesis of polysiloxane-aramid block copolymers

a PSX-diacid content in feed.

b Measured at a concentration of $0.5 \mathrm{~g} \mathrm{dl}^{-1}$ in DMAc at $30^{\circ} \mathrm{C}$.

condensation system for obtaining another type of polysiloxane-aramid block copolymers having higher inherent viscosities. ${ }^{6}$ Both dioxane as the cosolvent and CTMAC as the phase transfer catalyst were used in the reaction. However, the polycondensation progressed in a liquid-liquid two phase system to give polysiloxane-aramid block copolymers with inherent viscosities of $0.13-0.25 \mathrm{dl} \mathrm{g}^{-1}$ in $55-75 \%$ yield (Table I). Apparently, the solubility of PSX-diacid in the reaction mixture is not improved sufficiently and this polymerization system continues to limit the molecular weight of the block copolymers.

These values of inherent viscosities are not comparable to the molecular weights of the block copolymers, because DMAc, the solvent for viscosity measurement, is a good solvent for aramid and a poor solvent for polysiloxane. The observed viscosities should be somewhat lower in the block copolymers with high polysiloxane content compared with the viscosities of the copolymers with low polysiloxane content, if all block copolymers have nearly the same molecular weights.

The structure of the resultant polymers was confirmed by means of IR and NMR spec- 
Table II. Elemental analysis and intensity of ${ }^{1} \mathrm{H} N M R$ peaks of polysiloxane-aramid block copolymer Id

\begin{tabular}{|c|c|c|c|c|}
\hline & \multicolumn{3}{|c|}{ Elemental analysis } & \multirow{3}{*}{$\begin{array}{c}\mathrm{Si}-\mathrm{CH}_{3} / \\
\text { Aromatics } \\
\text { ratio }\end{array}$} \\
\hline & $\mathrm{C}$ & $\mathrm{H}$ & $\mathrm{N}$ & \\
\hline & $\%$ & $\%$ & $\%$ & \\
\hline Calcd for $\mathrm{A}^{\mathrm{a}}$ & 50.39 & 6.84 & 3.36 & 3.24 \\
\hline Calcd for $\mathbf{B}^{\mathrm{b}}$ & 62.35 & 5.27 & 6.11 & 0.83 \\
\hline Calcd for $\mathrm{C}^{\mathrm{c}}$ & 52.94 & 6.55 & 3.97 & 2.47 \\
\hline Calcd for $D^{d}$ & 60.02 & 5.61 & 5.64 & 1.11 \\
\hline Calcd for $n=\infty$ & 56.39 & 6.14 & 4.90 & 1.66 \\
\hline Found & 59.36 & 5.70 & 5.46 & 1.05 \\
\hline
\end{tabular}

a Structure A: BSX-aramid-PSX.

b Structure B: Aramid-PSX-aramid.

c Structure C: PSX-aramid-PSX-aramid-PSX.

d Structure D: aramid-PSX-aramid-PSX-aramid.

troscopy and elemental analysis. In the IR spectra, characteristic amide absorptions at $3300 \mathrm{~cm}^{-1}(\mathrm{~N}-\mathrm{H})$ and $1650 \mathrm{~cm}^{-1}(\mathrm{C}=\mathrm{O})$, and two absorptions due to siloxane group at 1090 and $1010 \mathrm{~cm}^{-1}$ appeared. In the ${ }^{1} \mathrm{H}$ NMR spectra, two remarkable peaks at $0 \mathrm{ppm}$ $\left(\mathrm{Si}-\mathrm{CH}_{3}\right)$ and $7.2-7.7 \mathrm{ppm}$ (aromatic $\mathrm{H}$ ) were observed.

It was suggested from the results of NMR and elemental analysis (Table II) that these block copolymers are composed on the average of five blocks, i.e., an aramid-PSXaramid-PSX-aramid structure.

\section{Properties of Block Copolymers}

The polysiloxane-aramid block copolymers were readily soluble in amide-type solvents such as DMAc, NMP, dimethyl sulfoxide, and pyridine. They were insoluble in other organic solvents including tetrahydrofuran, dioxane, chloroform, and benzene, which are good solvents for PSX-diacid. This solubility behavior was fairly comparable to that of the aramid homopolymer prepared by the reaction of equimolar amounts of 3,4'-ODA and IPA in the presence of triphenyl phosphite and pyridine, whose inherent viscosity was $0.54 \mathrm{dlg}^{-1}$ in DMAc. The translucent and flexible films could be cast from the DMAc

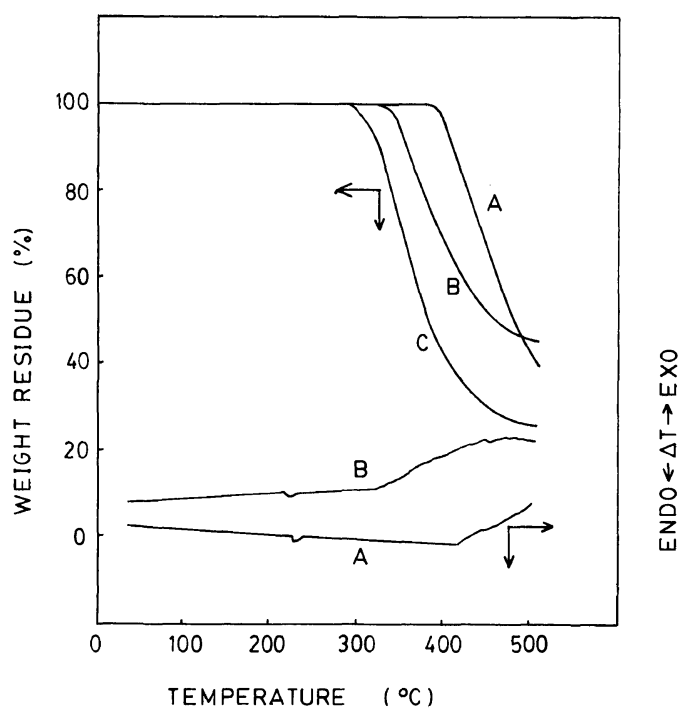

Figure 1. DTA and TG curves in air for (A) the aramid homopolymer, (B) polysiloxane-aramid block copolymer Id, and (C) the PSX-diacid, at a heating rate of $10^{\circ} \mathrm{C} \mathrm{min}^{-1}$.

Table III. Glass transition temperatures $\left(T_{\mathrm{g}}\right)$ of polysiloxane-aramid block copolymers

\begin{tabular}{|c|c|c|c|}
\hline \multirow[t]{2}{*}{ Polymer } & $\begin{array}{l}\text { Polysil- } \\
\text { oxane } \\
\text { content }\end{array}$ & $\begin{array}{c}T_{\mathrm{g}} \text { of poly- } \\
\text { siloxane } \\
\text { block }\end{array}$ & $\begin{array}{c}T_{\mathrm{g}} \text { of } \\
\text { aramid } \\
\text { block }\end{array}$ \\
\hline & $\%$ & ${ }^{\circ} \mathrm{C}$ & ${ }^{\circ} \mathrm{C}$ \\
\hline \multicolumn{4}{|l|}{ Polydimethyl- } \\
\hline Ia & 69 & -124 & 190 \\
\hline $\mathrm{Ib}$ & 64 & -124 & 205 \\
\hline Ic & 54 & -122 & 215 \\
\hline Id & 44 & -121 & 220 \\
\hline $\mathrm{Ie}$ & 37 & -121 & 225 \\
\hline \multicolumn{4}{|l|}{ Aramid } \\
\hline homopolymer & 0 & 一 & 240 \\
\hline
\end{tabular}

solutions on Teflon sheet, while the cast film on a glass plate adhered strongly to the surface and it was difficult to tear off.

Thermal behavior of the block copolymers was evaluated by DTA, TG, and DSC. Figure 1 shows the representative DTA and TG curves for block copolymer Id, parent PSXdiacid, and the aramid homopolymer. On the DTA curves in air, the onset of an exothermic reaction was observed for all the co- 
Polydimethylsiloxane-Aramid Block Copolymers

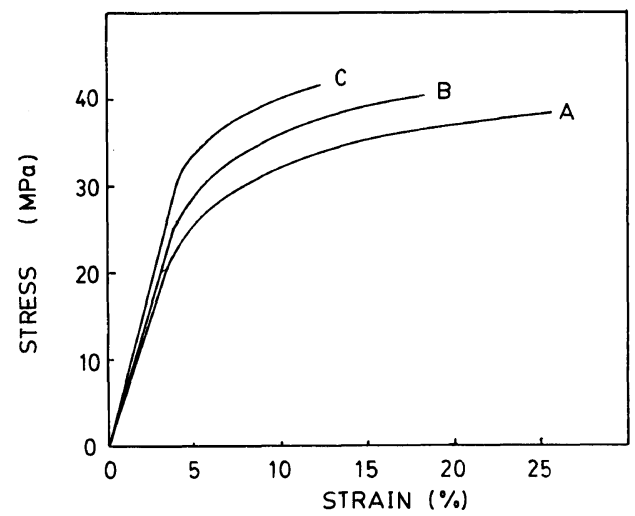

Figure 2. Stress-strain curves for polysiloxane-aramid block copolymer Ia (A), Ic (B), and Id (C).

polymers around $300^{\circ} \mathrm{C}$. The exothermic reaction was due apparently to decomposition of polysiloxane units. This is supported by the TG curves, which reveal the block copolymers to begin to lose weight above $300^{\circ} \mathrm{C}$ in air.

In addition, a small endothermic peak, probably due to the glass transition of aramid segment, was observed on the DTA curves in the range of $190-225^{\circ} \mathrm{C}$. These glass transition temperatures $\left(T_{\mathrm{g}}\right)$ were in good agreement with that of the aramid homopolymer $\left(240^{\circ} \mathrm{C}\right){ }^{7}$ The $T_{\mathrm{g}} \mathrm{s}$ of the polysiloxane segment, evaluated by DSC, were in the range from $-121--124^{\circ} \mathrm{C}$, which agrees well with that of polydimethylsiloxane homopolymer $\left(-126^{\circ} \mathrm{C}\right)$. All the results are summarized in Table III. It is obvious that the $T_{\mathrm{g}} \mathrm{s}$ of the polysiloxane phase increase with decreasing polysiloxane content and those of the aramid phase decrease with decreasing aramid content in the block copolymers. This inward shift phenomenon of the high $T_{\mathrm{g}}$ and low $T_{\mathrm{g}}$ is usual and has been reported for many block copolymers. ${ }^{8}$ The fact that two $T_{\mathrm{g}} \mathrm{s}$ were in good agreement with those of the homopolymers supports the micro-phase separated structures of polysiloxane and aramid blocks.

Stress-strain curves of the polysiloxanearamid block copolymer films are shown in
Table IV. Tensile properties of films of polysiloxane-aramid block copolymers

\begin{tabular}{|c|c|c|c|}
\hline \multirow{2}{*}{$\begin{array}{c}\text { Block } \\
\text { copolymer }\end{array}$} & $\begin{array}{l}\text { Tensile } \\
\text { strength }\end{array}$ & $\begin{array}{l}\text { Elongation } \\
\text { at break }\end{array}$ & $\begin{array}{l}\text { Tensile } \\
\text { modulus }\end{array}$ \\
\hline & $\mathrm{MPa}$ & $\%$ & $\mathrm{MPa}$ \\
\hline Ia & 38 & 25 & 650 \\
\hline Ib & 40 & 21 & 670 \\
\hline Ic & 41 & 18 & 690 \\
\hline Id & 42 & 12 & 800 \\
\hline Ie & 43 & 9 & 1000 \\
\hline \multicolumn{4}{|l|}{ Aramid } \\
\hline homopolymer & 62 & 5 & 1400 \\
\hline
\end{tabular}

Figure 2 and the tensile properties are summarized in Table IV. The films had flexible and ductile characteristics only slightly dependent on the aramid segment content, while the tensile properties of films of the polyoxyethylene-aramid and polybutadiene-aramid multi-block copolymers were highly dependent on aramid content. ${ }^{1-5}$ Low elongation at the break of these films was probably due to the rather low molecular weight of the block copolymers and inadequacy of the cast solvent (DMAc) for the copolymers.

All the properties of the present polysiloxane-aramid block copolymers were essentially the same as those of other polysiloxane-aramid block copolymers derived from $\alpha, \omega$-bis(3-aminopropyl)polydimethylsiloxane and carboxyl-terminated aramid oligomers reported previously: ${ }^{6}$

\section{REFERENCES}

1. Y. Imai, M. Kajiyama, S. Ogata, and M. Kakimoto, Polym. J., 16, 267 (1984).

2. Y. Imai, M. Kajiyama, S. Ogata, and M. Kakimoto, Polym. J., 17, 1173 (1985).

3. S. Ogata, M. Kakimoto, and Y. Imai, Macromolecules, 18, 851 (1985).

4. S. Ogata, H. Maeda, M. Kakimoto, and Y. Imai, Polym. J., 17, 935 (1985).

5. S. Ogata, H. Maeda, M. Kakimoto, and Y. Imai, $J$. Appl. Polym. Sci., in press.

6. M. Kajiyama, Y. Nishikata, M. Kakimoto, and Y. Imai, Polym. J., 18, 735 (1986). 
M. KaKimoto, M. KaJIYAMA, and Y. IMAI

7. Y. Imai, M. Kajiyama, S. Ogata, and M. Kakimoto, J. Polym. Sci., Polym. Chem. Ed., 22, 3183 (1984).
8. T. Inoue, S. Ogata, M. Kakimoto, and Y. Imai, Macromolecules, 17, 1417 (1984). 